\title{
Chitosan oligosaccharides downregulate the expression of E-selectin and ICAM-1 induced by LPS in endothelial cells by inhibiting MAP kinase signaling
}

\author{
YU LI ${ }^{1,2}$, QINGSONG XU ${ }^{1}$, PENG WEI ${ }^{1,2}$, LIKUN CHENG ${ }^{1,2}$, \\ QIANG PENG ${ }^{1,2}$, SHUGUANG LI ${ }^{1}$, HENG YIN ${ }^{1}$ and YUGUANG DU ${ }^{1}$ \\ ${ }^{1}$ Dalian Institute of Chemical Physics, Chinese Academy of Sciences, Dalian, Liaoning; \\ ${ }^{2}$ University of Chinese Academy of Sciences, Beijing, P.R. China
}

Received August 12, 2013; Accepted November 25, 2013

DOI: $10.3892 / \mathrm{ijmm} .2013 .1589$

\begin{abstract}
The expression of adhesion molecules in endothelial cells elicited by lipopolysaccharide (LPS) is involved in the adhesive interaction between endothelial cells and monocytes in inflammation. In this study, in order to characterize the anti-inflammatory effects of chitosan oligosaccharides (COS) on LPS-induced inflammation and to elucidate the underlying mechanisms, the mRNA levels of E-selectin and intercellular adhesion molecule-1 (ICAM-1) were measured in porcine iliac artery endothelial cells (PIECs). When these cells were treated with COS, the LPS-induced mRNA expression of E-selectin and ICAM-1 was reduced through the inhibition of the signal transduction cascade, p38 mitogen-activated protein kinase (MAPK)/extracellular regulated protein kinase $1 / 2(E R K 1 / 2)$ and nuclear factor- $\kappa \mathrm{B}(\mathrm{NF}-\kappa \mathrm{B})$. Moreover, through the inhibition of p38 MAPK and ERK1/2, COS suppressed the LPS-induced NF- $\kappa$ B p 65 translocation. We found that COS suppressed the phosphorylation of $\mathrm{p} 38$ MAPK and the translocation of NF- $\kappa \mathrm{B}$ p65 into the nucleus in a dose-dependent manner, and inhibited the adhesion of U973 cells to PIECs. Based on these results, it can be concluded that COS downregulate the expression of E-selectin and ICAM-1 by inhibiting the phosphorylation of MAPKs and the activation of NF- $\kappa \mathrm{B}$ in LPS-treated PIECs. Our study demonstrates the valuable anti-inflammatory properties of COS.
\end{abstract}

\section{Introduction}

Chitosan oligosaccharides (COS), consisting of D-glucosamine linked via $\beta-1,4$-glycosides, are derived from chitosan by

Correspondence to: Professor Yuguang Du or Professor Heng Yin, Dalian Institute of Chemical Physics, Chinese Academy of Sciences, 457 Zhongshan Road, Dalian, Liaoning 116023, P.R. China

E-mail: dyguang@gmail.com

E-mail: yinheng@dicp.ac.cn

Key words: chitosan oligosaccharides, lipopolysaccharide, mitogenactivated protein kinase, nuclear factor- $\kappa \mathrm{B}$, molecular adhesion chemical or enzymatic hydrolysis (1). It has been reported that COS exhibit various biological activities, such as antitumor (2) and antioxidant properties (3), owing to their low molecular weight, high absorption, solubility and biocompatibility (4). In addition, recent studies have paid more attention to the regulatory role of COS in inflammatory responses $(5,6)$.

Lipopolysaccharide (LPS), the major component of the outer membrane of Gram-negative bacteria, can act as an endotoxin and initiates serious inflammatory responses in vitro and in vivo $(7,8)$ by upregulating the expression of adhesion molecules and cytokines, such as E-selectin, intercellular adhesion molecule-1 (ICAM-1), vascular cell adhesion molecule-1 (VCAM-1) and tumor necrosis factor- $\alpha$ (TNF- $\alpha)(9,10)$. Endothelial cells are the target of inflammatory responses and thereby, of a number of severe disorders, including sepsis and multiple organ dysfunctions that occur via LPS stimulation (11). In this study, we detected the expression of the adhesion molecules, E-selectin and ICAM-1 in LPS-treated porcine iliac artery endothelial cells (PIECs), since the upregulation of adhesion molecules and the increased secretion of cytokines and chemokines are known to occur during endothelial cell activation (12-14).

The evolutionary conserved family of mitogen-activated protein kinases (MAPKs) includes extracellular p38 MAPK, extracellular regulated protein kinase (ERK) and c-Jun $\mathrm{N}$-terminal kinase (JNK) (15). Numerous environmental stresses, such as osmotic shock, ultraviolet irradiation, as well as LPS and pro-inflammatory cytokines, have been confirmed to activate MAPK signaling cascades in a variety of cell lines $(11,16)$. In addition, nuclear factor $-\kappa B(N F-\kappa B)$ and activator protein-1 (AP-1) have been identified as major downstream targets of MAPK signaling pathways, regulating, upon activation, a number of proteins, including cytokines and adhesion molecules $(8,17,18)$.

Accumulating evidence suggests that COS can attenuate inflammatory responses caused by stimuli, such as endotoxins, bacteria and cytokines $(19,20)$. However, the molecular mechanisms by which COS exert these effects in LPS-stimulated endothelial cells have not yet been fully elucidated. Whether the MAPK and/or NF- $\mathrm{B}$ signaling pathways are involved in the protective effects of COS in LPS-induced inflamma- 
tory responses in endothelial cells remains largely unknown. Therefore, the aim of the present study was to establish the in vitro roles of COS in LPS-induced inflammation in endothelial cells and to elucidate the underlying molecular mechanisms.

\section{Materials and methods}

Chemicals and reagents. COS were prepared in our laboratory (degree of deacetylation, $>95 \%$ ) according to a previously described method (21). Matrix-assisted laser desorption/ ionization (MALDI) - time-of-flight (TOF) mass spectrometry analysis indicated that the polymerization degree of the prepared COS was 3-7 (Fig. 1), as described in our previous study (4). The weight percentages of COS with degrees of polymerization of 3-7 were $3.7,16.1,28.8,37.2$ and $14.2 \%$, respectively, as previously described (22). LPS extract (from Escherichia coli serotype 055:B5), 3-(4,5-dimethylthiazol-2-yl)-2,5-diphenyltetrazolium bromide (MTT) and the proteasome inhibitor, MG132, were purchased from Sigma-Aldrich (St. Louis, MO, USA). The p38 MAPK inhibitor, SB203580, was purchased from Tocris Bioscience (Bristol, UK). The ERK1/2 inhibitor, PD98059, RPMI-1640 medium and fetal bovine serum (FBS) were obtained from Gibco/Invitrogen (Grand Island, NY, USA). Mouse anti-phospho-ERK (Thr202/Tyr204) monoclonal antibody, rabbit anti-ERK polyclonal antibody and Hoechst 33258 were purchased from Beyotime Institute of Biotechnology (Jiangsu, China). Anti-GAPDH polyclonal antibody, goat antirabbit IgG-HRP, goat anti-mouse IgG-HRP and goat anti-rabbit IgG-FITC were obtained from Santa Cruz Biotechnology (Santa Cruz, CA, USA). Rabbit anti-phospho-p38 (Thr180/Tyr182), as well as antibodies against p38, NF- $\mathrm{B}$ p65, IKKa and histone $\mathrm{H} 3$ were purchased from Cell Signaling Technology (Beverly, MA, USA).

Cell culture. PIECs were obtained from the Shanghai Institute of Cell Biology, Chinese Academy of Sciences (Shanghai, China) and were grown in RPMI-1640 medium containing $10 \%$ FBS, $2 \mathrm{mM}$ L-glutamine, $100 \mu \mathrm{g} / \mathrm{ml}$ streptomycin and $100 \mathrm{U} / \mathrm{ml}$ penicillin. Cells were incubated at $37^{\circ} \mathrm{C}$ in a humidified atmosphere of $5 \% \mathrm{CO}_{2}$. In all the experiments, cells from passages 3-10 were used; they were grown up to 70-80\% confluence prior to treatment with the different agents. The PIECs were pre-treated with the vehicle [phosphate-buffered saline (PBS), pH 7.4] or COS (50-200 mg/ml) in $1 \%$ FBS medium for $24 \mathrm{~h}$. They were then washed with PBS twice and exposed to $1 \mathrm{mg} / \mathrm{ml}$ LPS in $1 \%$ FBS medium for different periods of time.

Reverse transcription polymerase chain reaction ( $R T-P C R)$. Changes in the mRNA levels of E-selectin and ICAM-1 were assessed by RT-PCR. Total RNA was extracted from the treated cells using TRIzol reagent (Takara Biotechnology, Dalian, China) according to the manufacturer's instructions: The following primers were used for amplification: E-selectin forward, 5'-AAG CAA AGC AAC GAG GAC-3' and reverse, 5'-ACA GGT GAA GTG GCA GGT-3'; ICAM-1 forward, 5'-AAA CAC CAT CAT ACC CAA AGG-3' and reverse, 5'-TGC CAC GAC AAG TTA GCC-3'; and GAPDH forward, 5'-TTC CAC GGC ACA GTC AA-3' and reverse, 5'-GCA GGT CAG GTC CAC AA-3'. The thermal cycling program was as follows: initial denaturation for $5 \mathrm{~min}$ at $94^{\circ} \mathrm{C}$, followed by 35 cycles of $30 \mathrm{sec}$ at $94^{\circ} \mathrm{C}, 30 \mathrm{sec}$ at $52^{\circ} \mathrm{C}$ and $30 \mathrm{sec}$ at $72^{\circ} \mathrm{C}$. The amplified PCR products were electrophoresed on a $1.5 \%$ agarose gel containing $1 \mathrm{mg} / \mathrm{ml}$ ethidium bromide, visualized and photographed on a UV transilluminator (UVP, LLC BioImaging Systems, Upland, CA, USA).

Western blot analysis. PIECs $\left(2 \times 10^{6}\right)$ were directly lysed after treatment with a buffer containing $20 \mathrm{mmol} / \mathrm{l}$ Tris- $\mathrm{HCl}$ at $\mathrm{pH} 7.5,150 \mathrm{mmol} / 1 \mathrm{NaCl}, 1 \mathrm{mmol} / 1 \mathrm{Na}_{2}$ EDTA, $1 \mathrm{mmol} / 1$ EGTA, $1 \%$ Triton, $2.5 \mathrm{mmol} / 1$ sodium pyrophosphate, $1 \mathrm{mmol} / 1 \beta$-glycerophosphate, $1 \mathrm{mmol} / 1 \mathrm{Na}_{3} \mathrm{VO}_{4}$ and $1 \mathrm{mg} / \mathrm{ml}$ leupeptin, to which $1 \mathrm{mmol} / \mathrm{l}$ phenylmethanesulfonylfluoride (PMSF) was added before use. Nuclear and cytoplasmic fractions were separated using a nuclear and cytoplasmic protein extraction kit (Beyotime, Jiangsu, China). The concentration of the protein samples was measured using a bicinchoninic acid protein assay kit (Solarbio, Beijing, China). All samples were stored at $-80^{\circ} \mathrm{C}$ until further analysis. Equal amounts of protein (30 mg) were separated by SDS-PAGE (8-12\%) gel electrophoresis and electroblotted onto a $0.45-\mathrm{mm}$ polyvinylidene fluoride membrane. The membrane was blocked by incubation with $5 \%$ skim milk in Tris-buffered saline with $0.1 \%$ Tween-20 (TBST) for $1 \mathrm{~h}$ at room temperature, and incubated with primary antibodies overnight at $4^{\circ} \mathrm{C}$. After 3 washes in TBST, the membrane was incubated with HRP-/FITC-conjugated secondary antibodies for $1 \mathrm{~h}$ at room temperature. Respective proteins were detected using an enhanced chemoluminescence (ECL) assay kit and chemiluminescent signals were detected on an X-ray film. Densitometric analysis was performed using the PDI ImageWare system (Bio-Rad, Hercules, CA, USA).

MTT assay for cell viability. The viability of the PIECs was assessed by MTT assay. PIECs were plated into 96-well plates ( $5 \times 10^{3}$ cells/well) and incubated overnight with $150 \mathrm{ml}$ of RPMI-1640 solution supplemented with 10\% FBS. The cells were treated with $150 \mathrm{ml}$ of the vehicle or $\operatorname{COS}(50-800 \mu \mathrm{g} / \mathrm{ml})$ in RPMI-1640 with 1\% FBS. Following incubation for $24 \mathrm{~h}$, the PIECs were washed with PBS and incubated with MTT (1 $\mathrm{mg} / \mathrm{ml}$, final concentration) for a further $3 \mathrm{~h}$. The MTT solution was aspirated and $100 \mathrm{ml}$ of DMSO were added to solubilize the formazan crystals that formed inside the cells. The absorbance was measured at $490-\mathrm{nm}$ wavelength. The viability of the PIECs in each well was expressed as a percentage relative to the vehicle-treated group.

Monocyte cell adhesion assay. In order to monitor cell tracking, the PIECs were seeded into 24-well culture plates $\left(1 \times 10^{5}\right.$ cells/well) and were pre-treated with COS for $24 \mathrm{~h}$ and then stimulated with LPS $(1 \mathrm{mg} / \mathrm{ml})$ for $4 \mathrm{~h}$. U937 monocytes were incubated in RPMI-1640 medium containing 10\% FBS and with $10 \mathrm{mmol} / 1$ of the fluorescent dye, BCECF-AM, for $1 \mathrm{~h}$ in the dark at $37^{\circ} \mathrm{C}$. After washing twice with PBS, $5 \times 10^{4}$ cells/well were incubated with PIECs for $1 \mathrm{~h}$ in the dark at $37^{\circ} \mathrm{C}$. Non-adherent U937 cells were removed by washing gently with PBS. Adherent U937 cells were visualized under a FluoView microscope (Olympus, Japan) and in a fluorescence EM microplate reader (Gemini, USA) equipped with 488-nm excitation and 510-nm emission filters. Quantified fluorescence intensities were expressed as fold ratios relative to the vehicle-treated group. 
$\mathbf{A}$

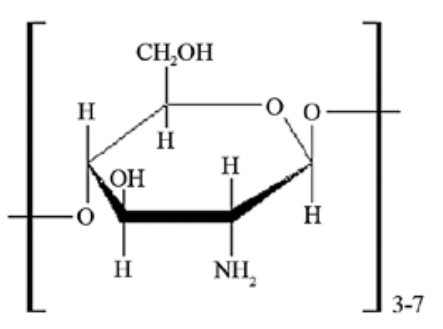

B

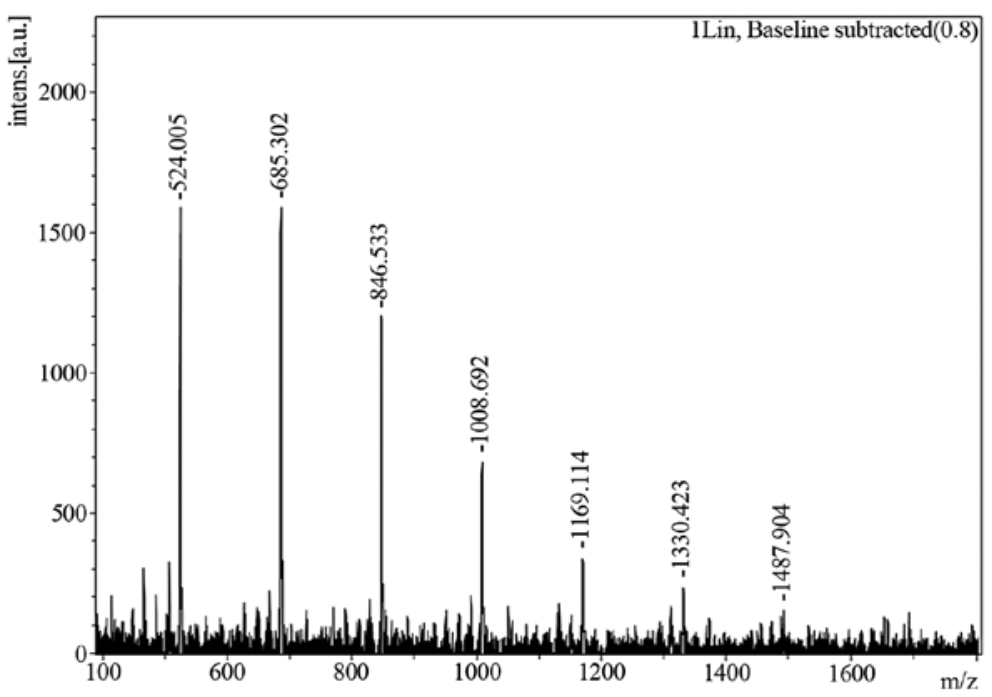

Figure 1. (A) Chemical structure of chitosan oligosaccharides (COS) and (B) mass spectra of a COS sample, as described in our previous study (4). X-axis, mass-to-charge ratio; y-axis, intensity in arbitrary units (a.u.).

Immunocytochemistry. PIECs at a density of $4 \times 10^{4}$ cells were cultured on glass coverslips. Following treatment, the cells were washed with ice-cold PBS and fixed in $4 \%$ formaldehyde/PBS for $30 \mathrm{~min}$ at room temperature, then incubated with $0.3 \%$ Triton X-100/PBS for $10 \mathrm{~min}$. After washing, the coverslips were blocked for $1 \mathrm{~h}$ at room temperature in $10 \%$ goat serum/PBS and then incubated with a 1:200 dilution of anti-p65 antibody in $10 \%$ goat serum/PBS for $1 \mathrm{~h}$ at $37^{\circ} \mathrm{C}$. After washing, the coverslips were incubated with a 1:200 dilution of FITC-conjugated goat anti-rabbit IgG in $10 \%$ goat serum/PBS for $45 \mathrm{~min}$ at room temperature. After washing, a 1:1,000 dilution of $10 \mathrm{mg} / \mathrm{ml}$ Hoechst 33258 was used to counterstain the nuclei for $10 \mathrm{~min}$. Finally, the coverslips were washed with PBS and mounted with aqueous mounting medium. Fluorescence signals were analyzed using a FluoView microscope.

Statistical analysis. Data are reported as the means $\pm \mathrm{SD}$ $(n=3-10)$. An unpaired Student's t-test was used to assess the significance of the differences between groups. A one-way ANOVA was used to compare the differences among 3 or more groups followed by Bonferroni multiple comparison tests, where applicable. A value of $\mathrm{P}<0.05$ was considered to indicate a statistically significant difference.

\section{Results}

LPS induces the mRNA expression of E-selectin and ICAM-1 in endothelial cells. LPS is known to induce critical inflammation by promoting the expression of cell adhesion molecules $(23,24)$. Thus, in this study, we first determined the mRNA expression of E-selectin and ICAM-1 in the PIECs exposed to LPS for various periods of time. Treatment with LPS $(1 \mu \mathrm{g} / \mathrm{ml})$ induced the mRNA expression of E-selectin and ICAM-1 in a time-dependent manner (Fig. 2A). Treatment with LPS for $1 \mathrm{~h}$ markedly enhanced E-selectin and ICAM-1
mRNA expression. The increase in the expression of E-selectin $(132.93 \pm 1.51 \%, \mathrm{P}<0.01)$ and ICAM-1 $(225.80 \pm 5.91 \%, \mathrm{P}<0.01)$ reached a peak at $3 \mathrm{~h}$ and then ceased and declined after $6 \mathrm{~h}$ of treatment (Fig. 2A).

Inhibition of MAPK and NF- $\kappa B$ pathways suppresses the mRNA expression of E-selectin and ICAM-1 in endothelial cells. We then examined the involvement of NF- $\kappa \mathrm{B}$, a transcription factor that plays a crucial role in inflammation, immunity, cell proliferation and apoptosis $(25-28)$. NF- $\kappa \mathrm{B}$ affected the LPS-induced E-selectin and ICAM-1 expression. The PIECs were pre-treated with the proteasome inhibitor, MG132 (10 mmol/l), which blocks the activation of NF- $\kappa$ B by preventing the degradation of $I \kappa B$ for $1 \mathrm{~h}$ prior to LPS challenge for $3 \mathrm{~h}$. As depicted in Fig. 2B, the inhibition of the activation of $N F-\kappa B$ significantly suppressed the mRNA expression of E-selectin and ICAM-1, which was reduced by $41.65 \pm 2.58 \%(\mathrm{P}<0.01)$ and $61.26 \pm 6.67 \%(\mathrm{P}<0.01)$, respectively, compared with the LPS-treated group.

We then determined whether MAPK and LPS are involved in the activation of NF- $\mathrm{NB}$ and in subsequent molecular adhesion. $\mathrm{NF}-\kappa \mathrm{B}$ is sequestered by $\mathrm{I} \kappa \mathrm{B}$ in the cytoplasm under normal conditions, whereas upon stimulation, IKK phosphorylates $\mathrm{I} \kappa \mathrm{B}$, inducing its degradation via the ubiquitination pathway and allowing free NF- $\kappa \mathrm{B}$ dimers (most commonly, the $\mathrm{p} 50 / \mathrm{p} 65$ dimer) to enter the nucleus $(29,30)$. As shown in Fig. 3, LPS caused a marked elevation of the IKK $\alpha$ protein level in the cytoplasm, as well as of the NF- $\mathrm{B}$ p 65 protein level in the nuclear fraction of PIECs. The inhibitors of p38 MAPK (SB203480, $25 \mathrm{mmol} / \mathrm{l}$ ) and ERK1/2 (PD98059, $25 \mathrm{mmol} / \mathrm{l})$ significantly attenuated these effects. The activation of p38 MAPK/ERK1/2 accelerates the translocation of the $\mathrm{NF}-\kappa \mathrm{B}$ dimer into the nucleus, where it binds to the promoter or enhancer regions of NF- $\kappa \mathrm{B}$-regulated genes to modulate gene transcription (31). In agreement with this, the inhibition of p38 MAPK and ERK1/2 significantly reduced the mRNA 
A
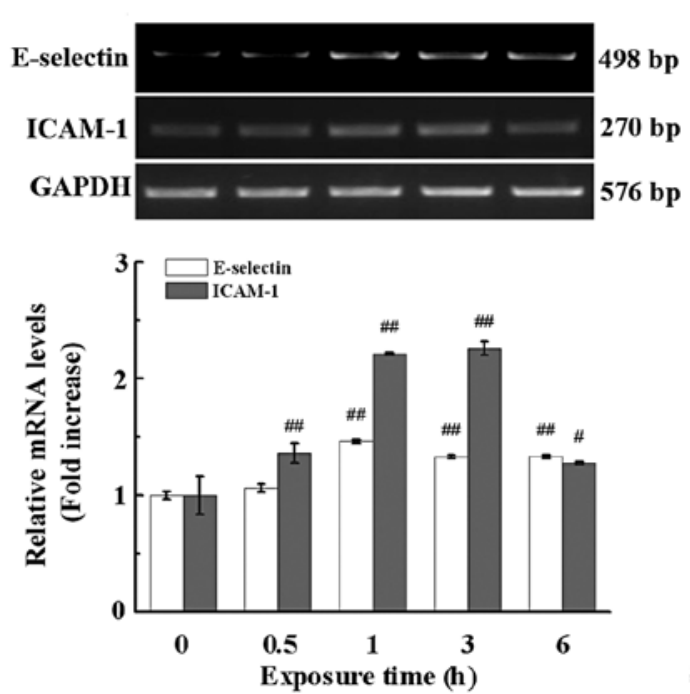

B
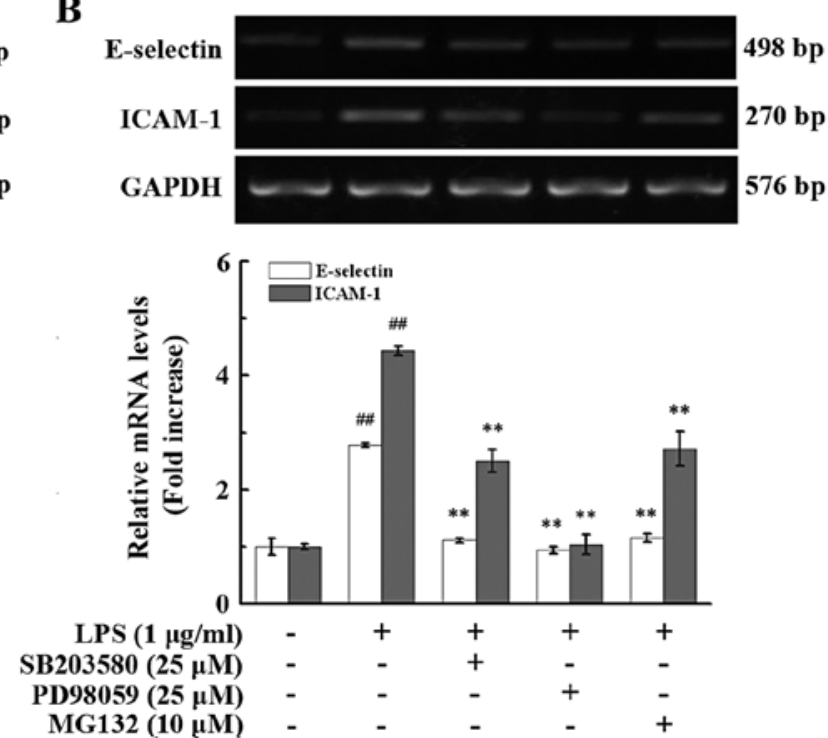

Figure 2. Inhibitors of p38 MAPK, extracellular regulated protein kinase 1/2 (ERK1/2) and nuclear factor- $\mathrm{kB}$ (NF-kB) reduce lipopolysaccharide (LPS)-induced mRNA expression of E-selectin and intercellular adhesion molecule-1 (ICAM-1) in porcine iliac artery endothelial cells (PIECs). Expression of E-selectin and ICAM-1 following (A) cell exposure to LPS $(1 \mu \mathrm{g} / \mathrm{ml})$ for the indicated periods of time and (B) pre-treatment with the p38 MAPK inhibitor, SB203850 $(25 \mu \mathrm{M})$, the ERK 1/2 inhibitor, PD98059 $(25 \mu \mathrm{M})$, or the NF-kB inhibitor, MG132 $(10 \mu \mathrm{M})$, for $1 \mathrm{~h}$ prior to exposure to LPS $(1 \mu \mathrm{g} / \mathrm{ml})$ for $3 \mathrm{~h}$. mRNA levels were evaluated by RT-PCR. Data are expressed as the means $\pm \mathrm{SD}(\mathrm{n}=3) .{ }^{\#} \mathrm{P}<0.05$ and ${ }^{\# \prime} \mathrm{P}<0.01$ compared to the control (untreated) group; ${ }^{* t} \mathrm{P}<0.01$ compared to the LPS-treated group.

A

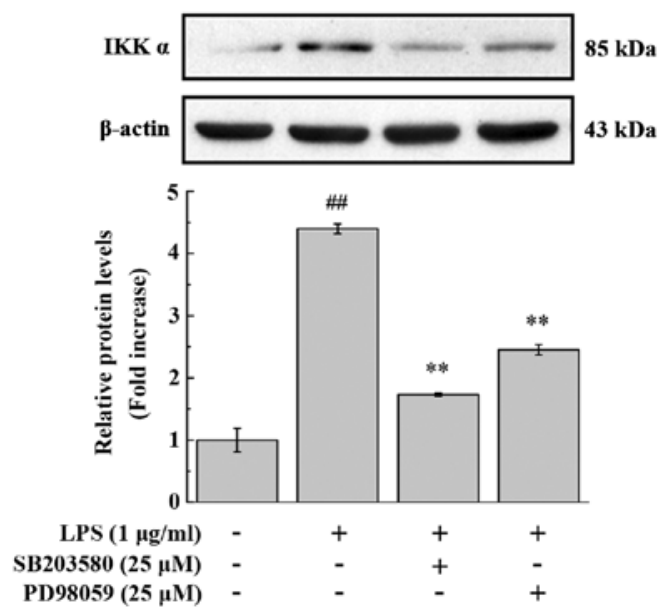

B

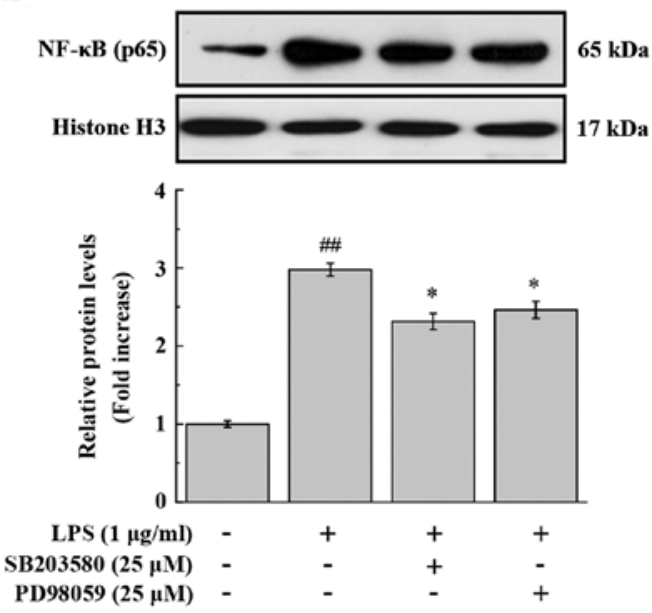

Figure 3. Lipopolysaccharide (LPS)-induced nuclear factor- $\kappa \mathrm{B}(\mathrm{NF}-\kappa \mathrm{B})$ translocation is suppressed by the inhibitors of p38 MAPK and extracellular regulated protein kinase 1/2 (ERK1/2) in porcine iliac artery endothelial cells (PIECs). The cells were pre-treated with or without the p38 MAPK inhibitor, SB203850 $(25 \mu \mathrm{M})$, or the ERK 1/2 inhibitor, PD98059 $(25 \mu \mathrm{M})$ for $1 \mathrm{~h}$ prior to incubation with LPS $(1 \mu \mathrm{g} / \mathrm{ml})$ for $1 \mathrm{~h}$. The nuclear fraction was subjected to western blot analysis for the detection of (A) IKK $\alpha$ and (B) NF- $\kappa$ B p65. Data are expressed as the means \pm SD (n=3). ${ }^{\# \#<} \mathrm{P}<0.01 \mathrm{compared}$ to the control (untreated) group; ${ }^{*} \mathrm{P}<0.05$ and ${ }^{* *} \mathrm{P}<0.01$ compared to the LPS-treated group.

expression of E-selectin and ICAM-1 in the PIECs (Fig. 2B). Compared to LPS stimulation alone (assigned a $100 \%$ level), the mRNA levels of E-selectin were decreased to $39.96 \pm 1.38 \%$ $(\mathrm{P}<0.01)$ and $33.81 \pm 2.35 \%(\mathrm{P}<0.01)$ by pre-treatment with p38 MAPK (SB203480) and ERK1/2 (PD98059) inhibitors, respectively, whereas the mRNA levels of ICAM-1 were reduced to $56.36 \pm 4.52 \%(\mathrm{P}<0.01), 23.44 \pm 3.91 \%(\mathrm{P}<0.01)$, respectively. Taken together, these data demonstrate that the p38 MAPK/ERK1/2 and NF- $\kappa$ B signaling pathways regulate the LPS-induced mRNA expression of E-selectin and ICAM-1 in the PIECs.
COS do not affect cell viability. The effect of COS on the viability of PIECs was evaluated by MTT assay. PIECs were treated with various concentrations of $\operatorname{COS}(50,100,200,400$, 600 and $800 \mu \mathrm{g} / \mathrm{ml}$ ). As shown in Fig. 4, neither concentration of COS had any effect on cell viability $(\mathrm{P}=0.158 ; \mathrm{P}=0.243$; $\mathrm{P}=0.596 ; \mathrm{P}=0.483 ; \mathrm{P}=0.127 ; \mathrm{P}=0.234$, respectively). Based on these results, we selected the concentration of $50-200 \mu \mathrm{g} / \mathrm{ml}$ COS for further experiments.

COS inhibit the MRNA expression of E-selectin and ICAM-1 and reduce the adhesion of monocytes to endothelial cells. A 
A
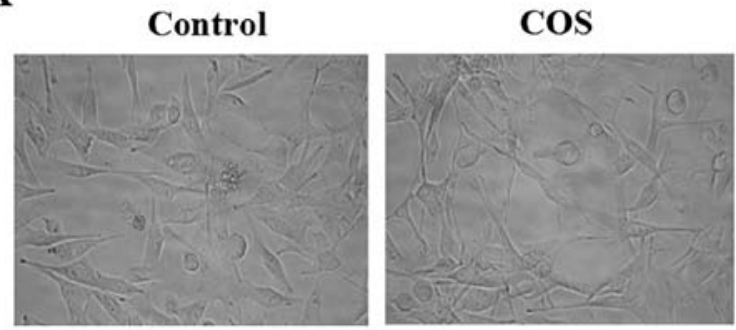

B

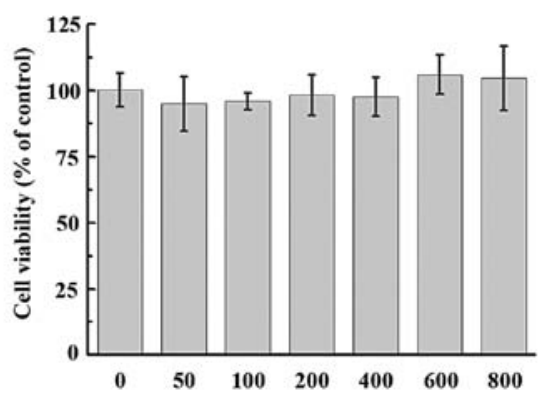

Figure 4. Chitosan oligosaccharides (COS) do not affect cell viability of porcine iliac artery endothelial cells (PIECs). (A) Representative images of PIECs treated with COS (0 and $200 \mu \mathrm{g} / \mathrm{ml})$ for $24 \mathrm{~h}(\mathrm{x} 400)$. (B) Cells were treated with the vehicle (control group) or COS $(50-800 \mu \mathrm{g} / \mathrm{ml})$ for $24 \mathrm{~h}$. Cell viability is presented as a percentage relative to the control group. Data are presented as the means \pm SD $(n=10)$.

few studies have provided evidence for the potentially beneficial effects of COS on oxidative and inflammatory damage, which occur via the improvement of the redox imbalance and limitation of cytokine production $(32,33)$. Moreover, under certain pathological conditions, endothelial cells are responsive and allow the migration of dendritic immune cells (34). In this study, we investigated the anti-inflammatory effects of COS on LPS-stimulated endothelial cells by treating PIECs with various concentrations of $\operatorname{COS}(50,100$ and $200 \mu \mathrm{g} / \mathrm{ml})$ for $24 \mathrm{~h}$ and subsequently incubating the cells with LPS for $3 \mathrm{~h}$. Treatment with COS reduced the mRNA expression of ICAM-1 and E-selectin (Fig. 5). This reduction was dosedependent and significant for ICAM-1, and significant for E-selectin only with pre-treatment with $200 \mu \mathrm{g} / \mathrm{ml} \mathrm{COS}$; at this concentration, the E-selectin and ICAM-1 mRNA expression levels were decreased by $38.14 \pm 7.29 \%(\mathrm{P}<0.01)$ and $70.29 \pm 12.86 \%(\mathrm{P}<0.01)$, respectively, compared with the LPS-treated group (Fig. 5).

Since COS inhibited the expression of adhesion molecules induced by LPS in the PIECs, we hypothesized that COS may attenuate monocyte adhesion to endothelial cells in LPS-induced inflammatory response. To confirm this, we assayed the adhesion of fluorescence-labeled U937 cells to LPS-treated PIECs. In this assay, LPS induced the adhesion of monocytes to endothelial cells, whereas COS inhibited this adhesion (Fig. 6A-C). Further confirmation of this result came from the quantification of the fluorescent intensity of labeled monocytes that adhered to PIECs; the latter were pre-treated with various concentrations of COS for $24 \mathrm{~h}$, followed by LPS stimulation. As expected, COS reduced the LPS-induced monocyte adhesion to PIECs in a dose-dependent manner $(50 \mathrm{mg} / \mathrm{ml}, 79.69 \pm 10.54 \%, \mathrm{P}<0.05 ; 100 \mathrm{mg} / \mathrm{ml}, 68.27 \pm 12.22 \%$,

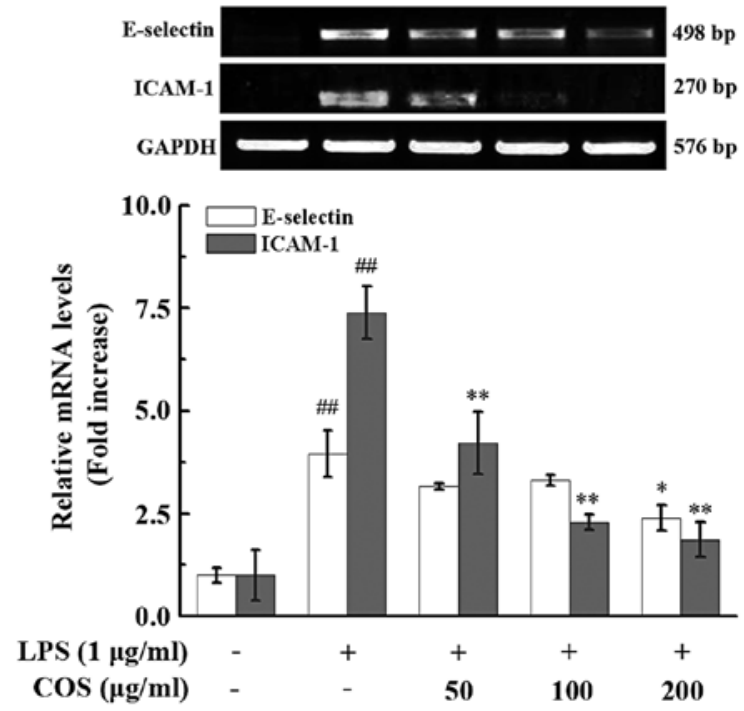

Figure 5. Chitosan oligosaccharides (COS) inhibit the lipopolysaccharide (LPS)-induced mRNA expression of E-selectin and intercellular adhesion molecule-1 (ICAM-1) in porcine iliac artery endothelial cells (PIECs). The cells were pre-treated with or without COS $(50-200 \mu \mathrm{g} / \mathrm{ml})$ for $24 \mathrm{~h}$ followed by treatment with LPS $(1 \mu \mathrm{g} / \mathrm{ml})$ for $3 \mathrm{~h}$. The mRNA levels of E-selectin and ICAM-1 were measured by RT-PCR. Data are presented as the means \pm SD $(\mathrm{n}=3) .{ }^{\# \#} \mathrm{P}<0.01$ compared to the control (untreated) group; ${ }^{*} \mathrm{P}<0.05$ and ${ }^{* *} \mathrm{P}<0.01$ compared to the LPS-treated group.

$\mathrm{P}<0.01 ; 200 \mathrm{mg} / \mathrm{ml}, 61.14 \pm 18.39 \%, \mathrm{P}<0.01$ vs. the LPS-treated group) (Fig. 6D).

COS inhibits the LPS-induced acvivation of the MAPK signaling pathway in endothelial cells. Based on our data, COS appears to play a protective role in LPS-induced inflammation in PIECs through the inhibition of the expression of the adhesion molecules, E-selectin and ICAM-1, whereas their upregulation by LPS is mediated by the p38 MAPK/ERK1/2 and NF- $\kappa B$ pathways. Thus, we investigated whether the inhibitory effects of COS are mediated through the MAPK signaling pathway.

The PIECs were pre-treated with various concentrations of $\operatorname{COS}$ for $24 \mathrm{~h}$ prior to exposure to $1 \mu \mathrm{g} / \mathrm{ml}$ LPS for $15 \mathrm{~min}$ and phosphorylated p38 MAPK and ERK1/2 were detected in the PIECs by western blot analysis. As shown in Fig. 7, the levels of phosphorylated p38 MAPK and ERK1/2 were increased upon treatment with LPS. By contrast, COS treatment significantly inhibited the phosphorylation of p38 MAPK and ERK1/2; this effect was dose-dependent for p38 MAPK. The maximal inhibitory effect of COS on the phosphorylation of p38 MAPK and ERK1/2 was observed at $200 \mu \mathrm{g} / \mathrm{ml}$, where the levels of the phosphorylated forms of these proteins decreased to $23.15 \pm 3.72 \%(\mathrm{P}<0.01)$ and $22.36 \pm 2.87 \%(\mathrm{P}<0.01)$ of the LPS-stimulated group, respectively (Fig. 7).

COS suppresses the translocation of NF- $\kappa B$ induced by LPS in endothelial cells. Our results revealed that the LPS-induced $\mathrm{NF}-\mathrm{KB}$ translocation is dependent on the MAPK signaling pathway. We then determined whether COS inhibits NF- $\mathrm{KB}$ activation by inhibiting the activation of the p38 MAPK/ ERK1/2 signaling pathway in PIECs. Treatment with LPS 

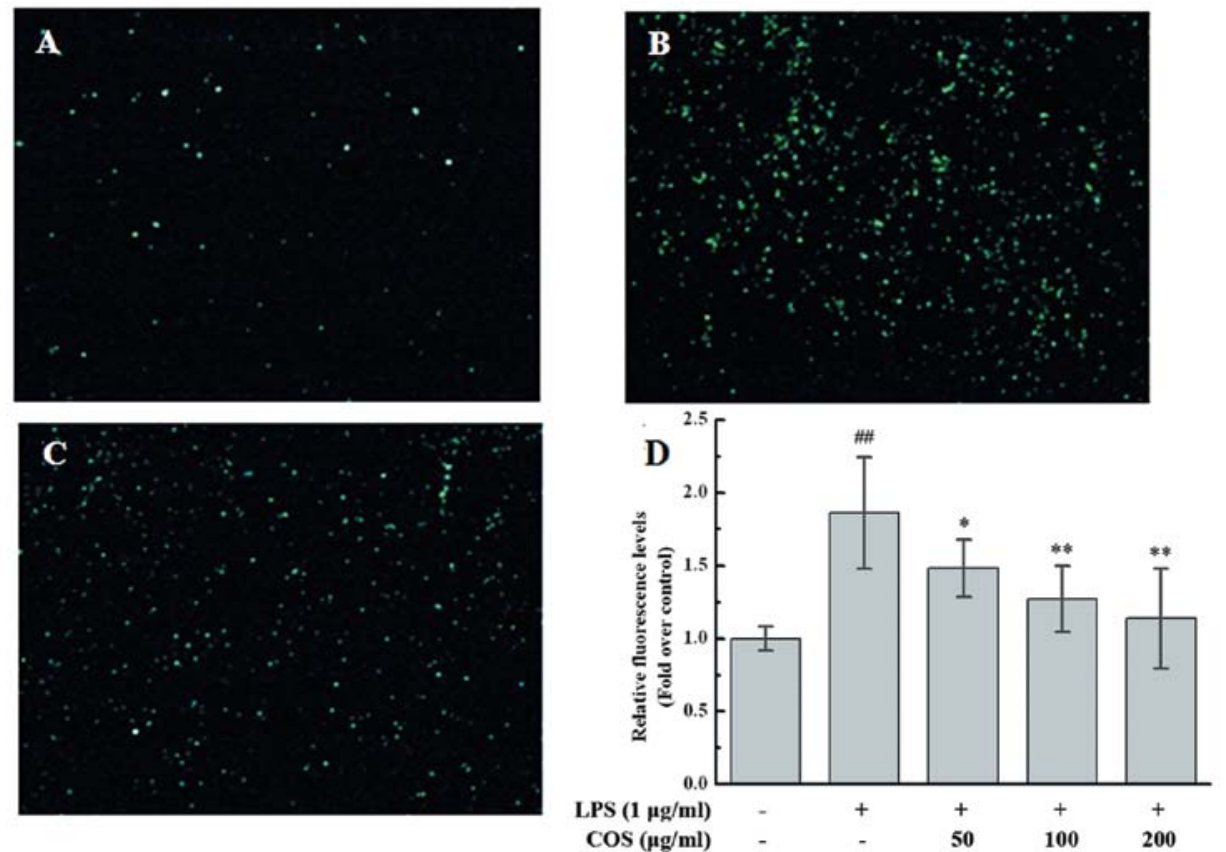

Figure 6. Chitosan oligosaccharides (COS) reduce the lipopolysaccharide (LPS)-induced U937 cell adhesion to porcine iliac artery endothelial cells (PIECs) in a dose-dependent manner. (A-C) Representative fluorescence images (x100) of U937 cell adhesion (1 h) to (A) vehicle-treated PIECs, (B) PIECs treated with LPS for $4 \mathrm{~h}$ and (C) PIECs treated with LPS for $4 \mathrm{~h}$ following $24 \mathrm{~h}$ of COS treatment. (D) Quantification of fluorescence intensities of PIECs pre-treated with COS $(50-200 \mu \mathrm{g} / \mathrm{ml})$ or the vehicle (control group) for $24 \mathrm{~h}$ prior to exposure to LPS $(1 \mu \mathrm{g} / \mathrm{ml})$ for $4 \mathrm{~h}$ and incubation with fluorescence-labelled U937 cells for $1 \mathrm{~h}$. Intensities were measured in a fluorescence microplate reader with 488 -nm excitation and 510-nm emission filters. Data are presented as the means \pm SD ( $\mathrm{n}=3$ ). ${ }^{\# \prime} \mathrm{P}<0.01$ compared to the control group; ${ }^{*} \mathrm{P}<0.05$ and ${ }^{* *} \mathrm{P}<0.01$ compared to the LPS-treated group.

A
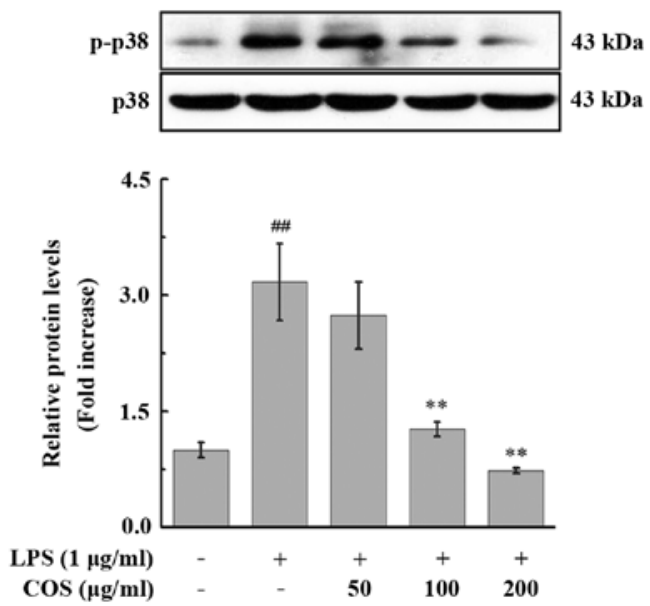

B
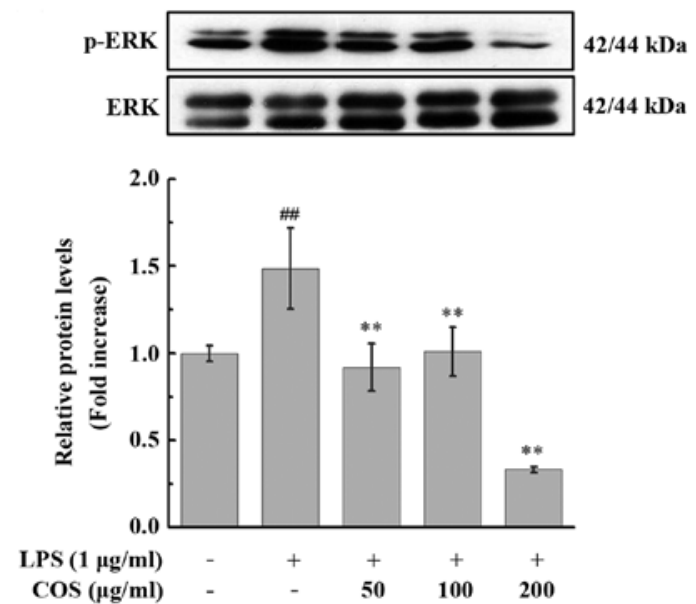

Figure 7. Chitosan oligosaccharides (COS) inhibit lipopolysaccharide (LPS)-activated p38 MAPK and extracellular regulated protein kinase 1/2 (ERK1/2) signaling in porcine iliac artery endothelial cells (PIECs). The cells were pre-treated with COS (50-200 $\mu \mathrm{g} / \mathrm{ml})$ or the vehicle (control group) for $24 \mathrm{~h}$ prior to LPS (1 $\mu \mathrm{g} / \mathrm{ml})$ treatment for $15 \mathrm{~min}$. The expression of (A) p38 MAPK and(B) ERK1/2 proteins and their phosphorylated forms was determined by western blot analysis. Data are presented as the means $\pm \mathrm{SD}(\mathrm{n}=3) .{ }^{\# \#} \mathrm{P}<0.01$ compared to the control (untreated) group; ${ }^{* *} \mathrm{P}<0.01 \mathrm{compared}$ to the LPS-treated group.

for $1 \mathrm{~h}$ increased the protein level of IKK $\alpha$ and promoted NF- $\kappa \mathrm{B}$ p65 nuclear translocation; these effects were significantly and dose-dependently attenuated by COS pretreatment (Fig. 8). To confirm the inhibitory effects of COS on LPS-induced NF- $\kappa B$ activation in the PIECs, NF- $\kappa \mathrm{B}$ p65 localization was determined by immunocytochemistry. As shown in Fig. 8C, treatment with LPS induced the translocation of NF- $\mathrm{kB}$ p65 into the nucleus, an effect that was considerably attenuated upon pre-treatment with COS.

\section{Discussion}

In the present study, we demonstrate that COS suppresses the LPS-induced expression of adhesion molecules in endothelial 
$\mathbf{A}$
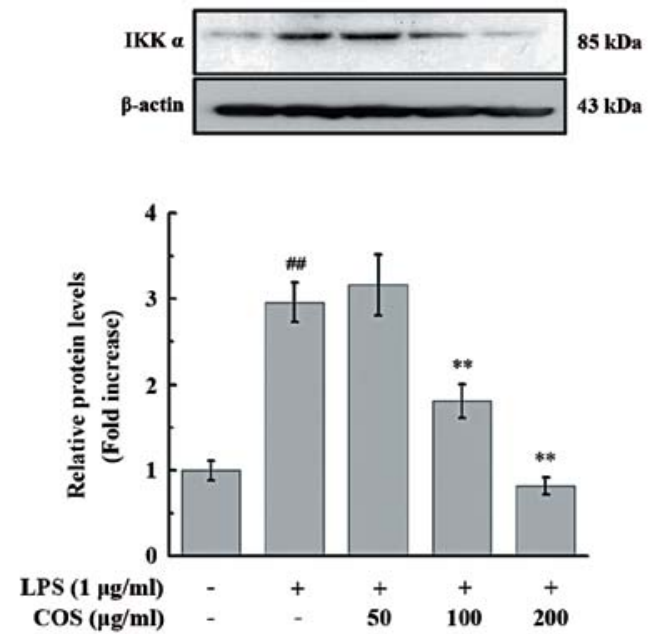

B
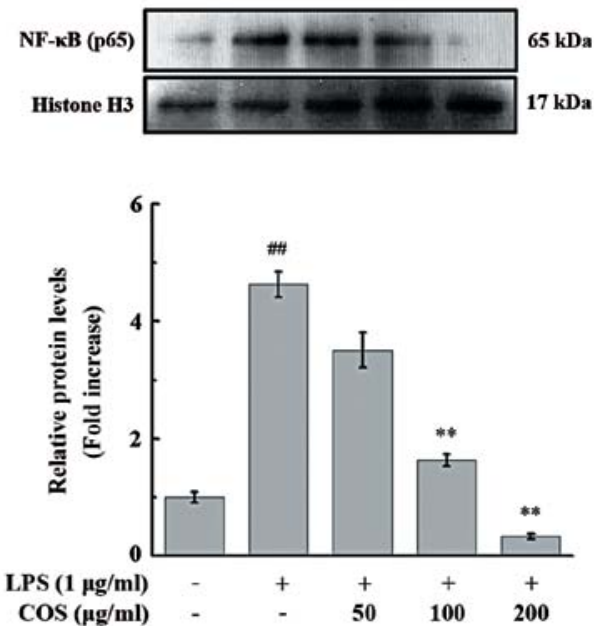

C

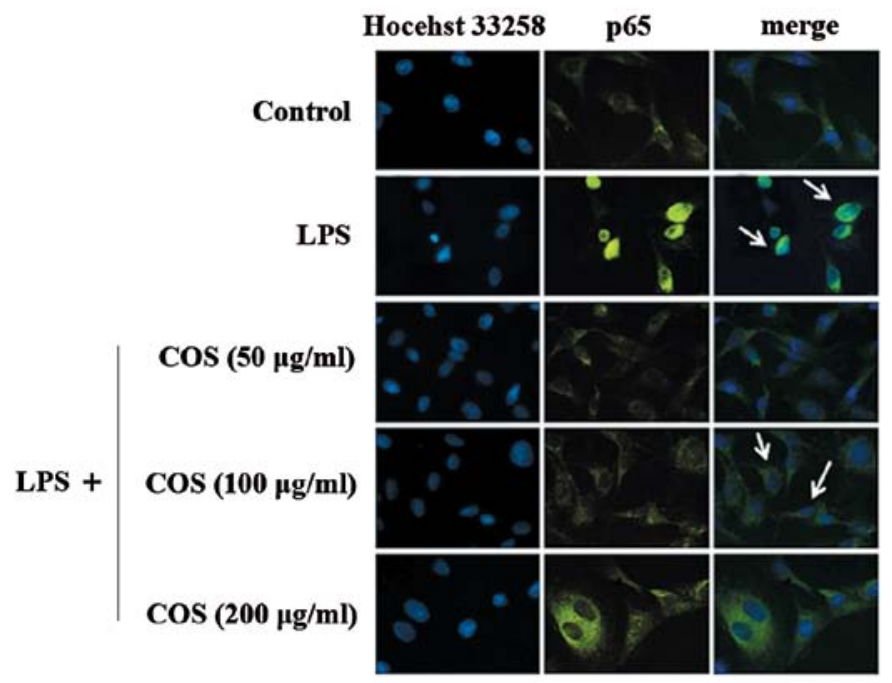

Figure 8. Lipopolysaccharide (LPS)-induced nuclear factor- $\mathrm{kB}(\mathrm{NF}-\mathrm{\kappa B})$ translocation is suppressed by chitosan oligosaccharides (COS) in a dose-dependent manner in porcine iliac artery endothelial cells (PIECs). The cells were pre-treated with or without COS (50-200 $\mu \mathrm{g} / \mathrm{ml})$ for $24 \mathrm{~h}$ prior to exposure to LPS $(1 \mu \mathrm{g} / \mathrm{ml})$ for $1 \mathrm{~h}$. The nuclear fraction was subjected to western blot analysis for the detection of (A) IKK $\alpha$ and (B) NF- $\mathrm{B}$ (p65). Histone H3 and $\beta$-actin were used as loading controls. Data are presented as the means $\pm \mathrm{SD}(\mathrm{n}=3) .{ }^{* \#} \mathrm{P}<0.01$ compared to the control (untreated) group; ${ }^{* *} \mathrm{P}<0.01$ compared to the LPS-treated group. (C) Localization of NF- $\mathrm{kB}$ (p65) as observed in immunocytochemistry using rabbit anti-p65 monoclonal primary antibody and FITC-conjugated goat anti-rabbit IgG secondary antibody (x400). Nuclei were stained with Hocehst 33258 (blue color). Merge, superposition of p-65 and Hocehst 33258 fields.

cells by inhibiting the activation of the MAPK and NF- $\mathrm{BB}$ signaling pathways and the consequent adhesion of monocytes to endothelial cells. Our results demonstrated that LPS induced the mRNA expression of E-selectin and ICAM-1 by activating the $\mathrm{p} 38 \mathrm{MAPK} / \mathrm{ERK} 1 / 2$ and $\mathrm{NF}-\kappa \mathrm{B}$ signaling pathways in PIECs. In line with these observations, the inhibtion of LPS-induced p38 MAPK/ERK1/2 and NF- $\mathrm{B}$ signaling by COS resulted in a decrease in the mRNA levels of E-selectin and ICAM-1 in PIECs.

One of the major findings of the present study is that COS significantly inhibited the LPS-induced mRNA expression of E-selectin and ICAM-1 in a dose-dependent manner, but had no effect on PIEC viability. The binding of circulating leukocytes to the microvascular endothelium is the initial event in leukocyte emigration and extravasation (35). The binding is mediated by endothelial ligands, such as E-selectin at the initial stages and ICAM-1 at subsequent stages $(23,36)$. The high expression of the adhesion molecules, E-selectin, ICAM-1 and VCAM-1, can promote endothelial cell migration and leukocyte adhesion to endothelial cells (37), which initiates the interaction between endothelial cells and leukocytes following tissue damage and is coupled with the induction of a variety of immune responses $(23,24)$. In our study, COS significantly reduced monocyte (U973 cell) adhesion to PIECs, which was induced by LPS. This result highlights the protective role of COS in LPS-induced inflammatory response in endothelial cells.

We also demonstrated that COS inhibited MAPK phosphorylation and NF- $\kappa \mathrm{B}$ translocation, which was induced by LPS in PIECs. Consistent with previous reports demonstrating that the tyrosine phosphorylation of p38 MAPK and ERK is involved in signal transduction occurring in LPS-stimulated endothelial cells $(23,38)$, and further mediates cellular 
responses through the NF- $\mathrm{B}, \mathrm{AP}-1$ and activating transcription factor 2 (ATF2) transcription factors (29). We found that the inhibition of p38 MAPK/ERK1/2 signaling suppressed the LPS-induced NF- $\kappa \mathrm{B}$ nuclear translocation in PIECs, leading to the reduced expression of E-selectin and ICAM-1; these results are in line with those of other studies, showing that the expression of E-selectin and ICAM-1 is associated with NF- $\kappa \mathrm{B}$ activation, since the $\mathrm{NF}-\kappa \mathrm{B}$ upstream promoter region contains binding sites for these two adhesion molecules $(10,11,30)$. Again in accordance with these reports, we found that COS inhibited the LPS-induced phosphorylation of p38 MAPK and ERK1/2 in PIECs, resulting in the observed dose-dependent suppression of the translocation of $\mathrm{NF}-\kappa \mathrm{B}$ into the nucleus. The latter can explain the inhibitory effects of COS on the mRNA expression of E-selectin and ICAM-1, which also showed dosedependence.

In conclusion, our results demonstrate that COS exerts its anti-inflammatory effects by inhibiting the acvitation of the LPS-induced p38 MAPK/ERK1/2 and NF- $\kappa \mathrm{B}$ signaling pathways, and consequently, the mRNA levels of E-selectin and ICAM-1, as well as monocyte adhesion to endothelial cells in vitro. Thus, COS may represent a promising therapeutic agent for the prevention of inflammatory responses in systemic diseases.

\section{Acknowledgements}

This study was supported by grants from the National Natural Science Foundation of China (nos. 31072065 and 31100589), and partly by The Twelfth Five Years National Science and Technology Support Plan Project (2011BAD26B02-3) and grant no. 2012AA021501 from the National High Technology Research and Development Program (863) of China.

\section{References}

1. Mourya VK, Inamdar NN and Choudhari YM: Chitooligosaccharides: synthesis, characterization and applications. Polym Sci Ser A 53: 583-612, 2011.

2. Xu WH, Jiang CQ, Kong XY, Liang Y, Rong M and Liu WS: Chitooligosaccharides and $\mathrm{N}$-acetyl-D-glucosamine stimulate peripheral blood mononuclear cell-mediated antitumor immune responses. Mol Med Rep 6: 385-390, 2012.

3. Liu HT, He JL, Li WM, et al: Chitosan oligosaccharides protect human umbilical vein endothelial cells from hydrogen peroxideinduced apoptosis. Carbohydr Polym 80: 1062-1071, 2010.

4. Zhang JN, Dang YB, Li S, et al: The effects of chitosan oligosaccharide on the activation of murine spleen $\mathrm{CD} 11 \mathrm{c}(+)$ dendritic cells via toll-like receptor 4. Carbohydr Polym 83: 1075-1081, 2011.

5. Yousef M, Pichyangkura R, Soodvilai S, Chatsudthipong V and Muanprasat C: Chitosan oligosaccharide as potential therapy of inflammatory bowel disease: therapeutic efficacy and possible mechanisms of action. Pharmacol Res 66: 66-79, 2012.

6. Ji Q, Deng J, Yu X, Xu Q, Wu H and Pan J: Modulation of proinflammatory mediators in LPS-stimulated human periodontal ligament cells by chitosan and quaternized chitosan. Carbohydr Polym 92: 824-829, 2013.

7. Chu X, Ci X, Wei M, et al: Licochalcone A inhibits lipopolysaccharide-induced inflammatory response in vitro and in vivo. J Agric Food Chem 60: 3947-3954, 2012.

8. Chen G, Li J, Ochani M, et al: Bacterial endotoxin stimulates macrophages to release HMGB1 partly through CD14- and TNF-dependent mechanisms. J Leukoc Biol 76: 994-1001, 2004.

9. $\mathrm{Hu} \mathrm{Y}$, Chen X, Duan $\mathrm{H}, \mathrm{Hu}$ Y and $\mathrm{Mu} \mathrm{X}$ : Chinese herbal medicinal ingredients inhibit secretion of IL-6, IL-8, E-selectin and TXB(2) in LPS-induced rat intestinal microvascular endothelial cells. Immunopharmacol Immunotoxicol 31: 550-555, 2009.
10. Zou LY, Yang SL, Champattanachai V, et al: Glucosamine improves cardiac function following trauma-hemorrhage by increased protein O-GlcNAcylation and attenuation of NF- $\mathrm{KB}$ signaling. Am J Physiol Heart Circ Physiol 296: H515-H523, 2009.

11. Yan WS, Zhao KS, Jiang Y, et al: Role of p38 MAPK in ICAM-1 expression of vascular endothelial cells induced by lipopolysaccharide. Shock 17: 433-438, 2002.

12. Tanigawa N, Hagiwara M, Tada $\mathrm{H}$, et al: Acacetin inhibits expression of E-selectin on endothelial cells through regulation of the MAP kinase signaling pathway and activation of NF- $\kappa \mathrm{B}$. Immunopharmacol Immunotoxicol 35: 471-477, 2013.

13. Pina-Canseco Mdel S, Paez-Arenas A, Masso F, et al: Protein C activation peptide inhibits the expression of ICAM-1, VCAM-1, and interleukin- 8 induced by TNF- $\alpha$ in human dermal microvascular endothelial cells. Folia Histochem Cytobiol 50: 407-413, 2012.

14. Shreeniwas R, Koga S, Karakurum M, et al: Hypoxia-mediated induction of endothelial cell interleukin-1 alpha. An autocrine mechanism promoting expression of leukocyte adhesion molecules on the vessel surface. J Clin Invest 90: 2333-2339, 1992.

15. Qiao Y, Ruan YY, Xiong CN, et al: Chitosan oligosaccharides suppressant LPS binding to TLR4/MD-2 receptor complex. Carbohydr Polym 82: 405-411, 2010.

16. Yomogida S, Hua J, Sakamoto K and Nagaoka I: Glucosamine suppresses interleukin-8 production and ICAM-1 expression by TNF- $\alpha$-stimulated human colonic epithelial HT-29 cells. Int J Mol Med 22: 205-211, 2008.

17. Egorina EM, Sovershaev TA, Hansen JB and Sovershaev MA: BMP-2 inhibits TF expression in human monocytes by shutting down MAPK signaling and AP-1 transcriptional activity. Thromb Res 129: E106-E111, 2012.

18. Hippenstiel S, Soeth S, Kellas B, et al: Rho proteins and the p38-MAPK pathway are important mediators for LPS-induced interleukin-8 expression in human endothelial cells. Blood 95: 3044-3051, 2000.

19. Bahar B, O'Doherty JV, Maher S, McMorrow J and Sweeney T: Chitooligosaccharide elicits acute inflammatory cytokine response through AP-1 pathway in human intestinal epitheliallike (Caco-2) cells. Mol Immunol 51: 283-291, 2012.

20. Simunek J, Brandysova V, Koppova I and Simunek J Jr: The antimicrobial action of chitosan, low molar mass chitosan, and chitooligosaccharides on human colonic bacteria. Folia Microbiol (Praha) 57: 341-345, 2012.

21. Zhang H, Du Y, Yu X, Mitsutomi M and Aiba S: Preparation of chitooligosaccharides from chitosan by a complex enzyme. Carbohydr Res 320: 257-260, 1999.

22. Dou J, Tan C, Du Y, Bai X, Wang K and Ma X: Effects of chitooligosaccharides on rabbit neutrophils in vitro. Carbohydr Polym 69: 209-213, 2007.

23. Shan Y, Lin N, Yang X, et al: Sulphoraphane inhibited the expressions of intercellular adhesion molecule-1 and vascular cell adhesion molecule-1 through MyD88-dependent toll-like receptor-4 pathway in cultured endothelial cells. Nutr Metab Cardiovasc Dis 22: 215-222, 2012.

24. Lush CW, Cepinskas G and Kvietys PR: LPS tolerance in human endothelial cells: reduced PMN adhesion, E-selectin expression, and NF-kappa B mobilization. Am J Physiol Heart Circ Physiol 278: H853-H861, 2000.

25. Junkins RD, MacNeil AJ, Wu Z, McCormick C and Lin TJ: Regulator of calcineurin 1 suppresses inflammation during respiratory tract infections. J Immunol 190: 5178-5186, 2013.

26. Viatour P, Merville MP, Bours V and Chariot A: Phosphorylation of NF-kappaB and IkappaB proteins: implications in cancer and inflammation. Trends Biochem Sci 30: 43-52, 2005.

27. Luco S, Delmas O, Vidalain PO, Tangy F, Weil R and Bourhy $\mathrm{H}$ : RelAp43, a member of the NF- $\kappa \mathrm{B}$ family involved in innate immune response against Lyssavirus infection. PLoS Pathog 8: e1003060, 2012.

28. Wu B, Yao H, Wang S and Xu R: DAPK1 modulates a curcumininduced $\mathrm{G} 2 / \mathrm{M}$ arrest and apoptosis by regulating STAT3, NF- $\mathrm{KB}$, and caspase- 3 activation. Biochem Biophys Res Commun 434: 75-80, 2013.

29. Park EJ, Cheenpracha S, Chang LC and Pezzuto JM: Suppression of cyclooxygenase- 2 and inducible nitric oxide synthase expression by epimuqubilin A via IKK/I $\mathrm{B} / \mathrm{NF}-\kappa \mathrm{B}$ pathways in lipopolysaccharide-stimulated RAW 264.7 cells. Phytochem Lett 4: 426-431, 2011. 
30. O'Connell MA, Bennett BL, Mercurio F, Manning AM and Mackman N: Role of IKK1 and IKK2 in lipopolysaccharide signaling in human monocytic cells. J Biol Chem 273: 30410-30414, 1998.

31. Murayama R, Kobayashi M, Takeshita A, et al: MAPKs, activator protein-1 and nuclear factor-kappa $B$ mediate production of interleukin-1 beta-stimulated cytokines, prostaglandin E-2 and MMP-1 in human periodontal ligament cells. J Periodont Res 46: $568-575,2011$

32. Liu HT, Li WM, Xu G, et al: Chitosan oligosaccharides attenuate hydrogen peroxide-induced stress injury in human umbilical vein endothelial cells. Pharmacol Res 59: 167-175, 2009.

33. Vo TS, Kong CS and Kim SK: Inhibitory effects of chitooligosaccharides on degranulation and cytokine generation in rat basophilic leukemia RBL-2H3 cells. Carbohydr Polym 84: 649-655, 2011.

34. Bianchi G, D'Amico G, Varone L, Sozzani S, Mantovani A and Allavena P: In vitro studies on the trafficking of dendritic cells through endothelial cells and extra-cellular matrix. Dev Immunol 7: 143-153, 2000.
35. Ogawa H, Rafiee P, Heidemann J, et al: Mechanisms of endotoxin tolerance in human intestinal microvascular endothelial cells. J Immunol 170: 5956-5964, 2003.

36. Albelda SM, Smith CW and Ward PA: Adhesion molecules and inflammatory injury. FASEB J 8: 504-512, 1994.

37. Ju Y, Hua J, Sakamoto K, Ogawa H and Nagaoka I: Modulation of TNF- $\alpha$-induced endothelial cell activation by glucosamine, a naturally occurring amino monosaccharide. Int J Mol Med 22: 809-815, 2008

38. Binion DG, Heidemann J, Li MS, Nelson VM, Otterson MF and Rafiee P: Vascular cell adhesion molecule-1 expression in human intestinal microvascular endothelial cells is regulated by PI 3-kinase/Akt/MAPK/NF-kappa B: inhibitory role of curcumin. Am J Physiol Gastrointest Liver Physiol 297: G259-G268, 2009. 